\title{
Common Carotid Artery Bifurcation Levels Related to Clinical Relevant Anatomical Landmarks
}

\author{
Niveles de Bifurcación de la Arteria Carótida Común en Relación \\ a Puntos de Referencia Anatómicos Relevantes en Clínica \\ "Rogério Alves Ribeiro; *João Alberto de Souza Ribeiro; *Omar Andrade Rodrigues Filho; \\ *Abadio Gonçalves Caetano \& **Valéria Paula Sassoli Fazan
}

RIBEIRO, R. A.; RIBEIRO, J. A. S.; RODRIGUES FILHO, O. A.; CAETANO, G. A. \& FAZAN, V. P. S. Common carotid artery bifurcation levels related to clinical relevant anatomical landmarks. Int. J. Morphol., 24(3):413-416, 2006.

SUMMARY: In head and neck surgery, the common carotid arteries are important landmarks, defining dissection plane during radical neck surgeries. The objectives of the present study were to add information on the diameter of the carotid arteries and to correlate the common carotid artery (CCA) bifurcation level with important anatomical landmarks used regularly in clinical practice.

Forty-six necks from male embalmed human cadavers were evaluated. The CCA as the external (ECA) and internal (ICA) carotid arteries diameters were studied with the aid of an electronic digital caliper. No differences were found between sides in any level studied. The CCA bifurcation level was measured in relation to clinically relevant anatomical landmarks (superior level of the thyroid cartilage, mandible angle and ear lobe) and the bifurcation level according to the cervical vertebra level was also investigated.

Our study shows that the superior border of the thyroid cartilage was the most stable anatomical landmark for predicting the CCA bifurcation level. It is important to mention that from all the landmarks studied, the cervical vertebra was the only one to show differences between sides, with the left side bifurcation level more variable than the right side.

KEY WORDS: Vascular anatomy; Surgical anatomy; Neck surgery; Carotid artery; Arterial diameter.

\section{INTRODUCTION}

For most of the large arterial vessels, surgeons can rely on a constant anatomy. In head and neck surgery, the common carotid arteries are important landmarks, defining the plane of the dissection during radical neck surgery (Ord \& Ward-Booth, 1986). Conventional angiography is considered the most accurate technique for diagnosis of carotid bifurcation diseases, such as stenosis (Schwartz et al., 1992). Thus, accurate evaluation of the carotid bifurcation level with non invasive techniques remains an important goal and external anatomical landmarks can be clinically useful in predicting the bifurcation level of the carotid artery. Despite the large number of anatomical variations descriptions of the carotid arteries, very little information is available in the literature on the diameter of these vessels. Knowledge of the size of these vessels might be important in improving local surgical techniques and also the radiological diagnosis of neck pathologies.

The objectives of the present study were to add new information on the diameter of the carotid arteries and to correlate the common carotid artery (CCA) bifurcation level with important anatomical landmarks used regularly in clinical practice.

\section{MATERIAL AND METHOD}

Forty-six heads from male embalmed human cadavers were studied. The age of death ranged from 37 to 74 years

* Department of Biological Sciences, Federal University of Triângulo Mineiro, Uberaba, Minas Gerais, Brazil.

** Department of Surgery and Anatomy, School of Medicine of Ribeirão Preto, University of São Paulo, Ribeirão Preto, São Paulo, Brazil.

Support: CNPq (Conselho Nacional de Desenvolvimento Científico e Tecnológico) grant No 501230/2003-3, FAPESP (Fundação de Amaparo a Pesquisa do Estado de São Paulo) grants No 02/09406-5, 04/01390-8 and 04/09139-2, FAEPA (Fundação de Apoio ao Ensino e Pesquisa do Hospital das Clínicas da Faculdade de Medicina de Ribeirão Preto). Brazil. 
and all specimens were fixed in $10 \%$ formaldehyde solution. Anomalous tortuosities, dilatations, aneurisms or atheromatous/occlusive disease samples were discarded at the beginning of the study. Abnormal origins of the carotid arteries, such as those arising from the retroesophageal subclavian arteries, were also discarded. The necks have been partially dissected by medical students during the previous years and further dissections were done by the authors, with the aid of a D. F. Vasconcellos M-90 surgical microscope. With the aid of an electronic digital caliper (range of 0 $300 \mathrm{~mm}$, resolution $0.01 \mathrm{~mm}$, Gehaka, SP, Brazil) the arterial length and diameters were measured as follows: total length of the common carotid arteries (CCA), external diameter of the CCA at origin level, external diameter of the CCA at bifurcation level, external diameter of the internal carotid artery (ICA) and external diameter of external carotid artery (ECA), both at origin levels. With the aid of the same caliper, the CCA bifurcation level was measured in relation to clinically relevant anatomical landmarks as follows: superior level of the thyroid cartilage, mandible angle and ear lobe. The bifurcation level of the CCA in relation to the cervical vertebra was also investigated. All measurement values were obtained in $\mathrm{cm}$ and are presented as mean \pm standard error of mean (SEM). Data were tested for normal distribution by the Kolmogorov-Smirnov normality test (Ong \& LeClare, 1968; Rosenthal, 1968). If the data presented a normal distribution, comparisons between sides were made by the paired Student's t-test. Otherwise, comparisons were made by the nonparametric Wilcoxon signed rank test (Wilcoxon, 1945). Significant differences were considered when $\mathrm{p}<0.05$.

\section{RESULTS}

Fifty four cadavers were evaluated in total. One female cadaver was discarded by the presence of a retroesophageal subclavian artery (Fazan et al., 2003), one male cadaver was discarded by a presence of a retroesophageal subclavian artery, associated with other anatomical variations (Fazan et al., 2004) and two male cadavers were discarded by the presence of abnormal tortuosities of the cervical ICA (unpublished data). Four female cadavers, despite the presence of normal CCA, were also discarded due to the small number of female samples in this study. For the 46 male cadavers included in this study, the average length of the right CCA was $9.6 \pm 0.1 \mathrm{~cm}$ while the left CCA measured $12.1 \pm 0.2 \mathrm{~cm}$ in length, with a significant difference between sides. The CCA diameters as the ECA and ICA diameters are shown on Table I. No differences were found between sides in any level studied. Nevertheless, the CCA diameter at the bifurcation was significantly larger than at the origin level on both sides and, also larger than the ECA and ICA at origin levels. A significant larger diameter at the ICA origin level, compared to the ECA origin level, was also observed on both sides.

Table I: Arterial diameter $(\mathrm{cm})$ of the carotid arteries on both sides. * Indicates difference between origin and bifurcation levels at the same side. \# Indicates difference from the external carotid artery on the same side. No differences between sides were noted. Data are presented as mean \pm standard error of mean (SEM).

\begin{tabular}{lcc}
\hline & Right & Left \\
\cline { 2 - 3 } Common carotid artery & & \\
Origin & $0.91 \pm 0.02$ & $0.94 \pm 0.02$ \\
Bifurcation & $1.29 \pm 0.04^{*}$ & $1.32 \pm 0.04^{*}$ \\
External carotid artery & $0.73 \pm 0.02$ & $0.71 \pm 0.02$ \\
Internal carotid artery & $0.80 \pm 0.03 \#$ & $0.80 \pm 0.02 \#$ \\
\hline
\end{tabular}

On the right side, $40 \%$ of the CCA presented their bifurcation at the $3^{\text {rd }}$ cervical vertebra (C III) level while the other $60 \%$ had their bifurcation at the $2^{\text {nd }}$ cervical vertebra (C II) level. On the left side, one cadaver showed a CCA bifurcation at the $4^{\text {th }}$ cervical vertebra (C IV) while $20 \%$ had the bifurcation at C III level and $78 \%$ at $\mathrm{C}$ II level. The distance of the CCA bifurcation from the superior border of the thyroid cartilage varied from -0.8 (below the level) to $1.9 \mathrm{~cm}$ (above the level), with an average of $0.9 \pm 0.1 \mathrm{~cm}$ on the right side, with no differences between sides. From the mandible angle, the distance of the CCA bifurcation varied from 0.5 to $4.4 \mathrm{~cm}$ below the angle, with an average of $1.7 \pm$ $0.2 \mathrm{~cm}$, also with no significant differences between sides (Fig. 1). From the ear lobe, the distance of the CCA bifurcation varied from 2.9 to 6.7 below the lobe, with an average of $4.5 \pm 0.2 \mathrm{~cm}$ (Fig. 1). No differences between sides were observed.

\section{DISCUSSION}

It is commonly accepted that the CCA bifurcation occurs about the level of C IV (Lemmi et al., 1968, Vitek \& Reaves, 1973) for radiological purposes. Nevertheless, most anatomical text books and references in the literature describe the upper border of the thyroid cartilage as the bifurcation level (Agur \& Lee, 1991; Ord \& Ward-Booth). With the advent of the radiological exams, and the need of a more accurate interpretation of them, external anatomical landmarks turned to be useful in regular clinical practice, especially during the percutaneous carotid angiography. Our findings call attention to the fact that the vertebral level of the carotid arteries bifurcation are higher than C IV and also, when this anatomical landmark is considered, there might be differences between sides on the same individual. Radiologist should take these differences into consideration when correctly interpreting radiographic exams. 

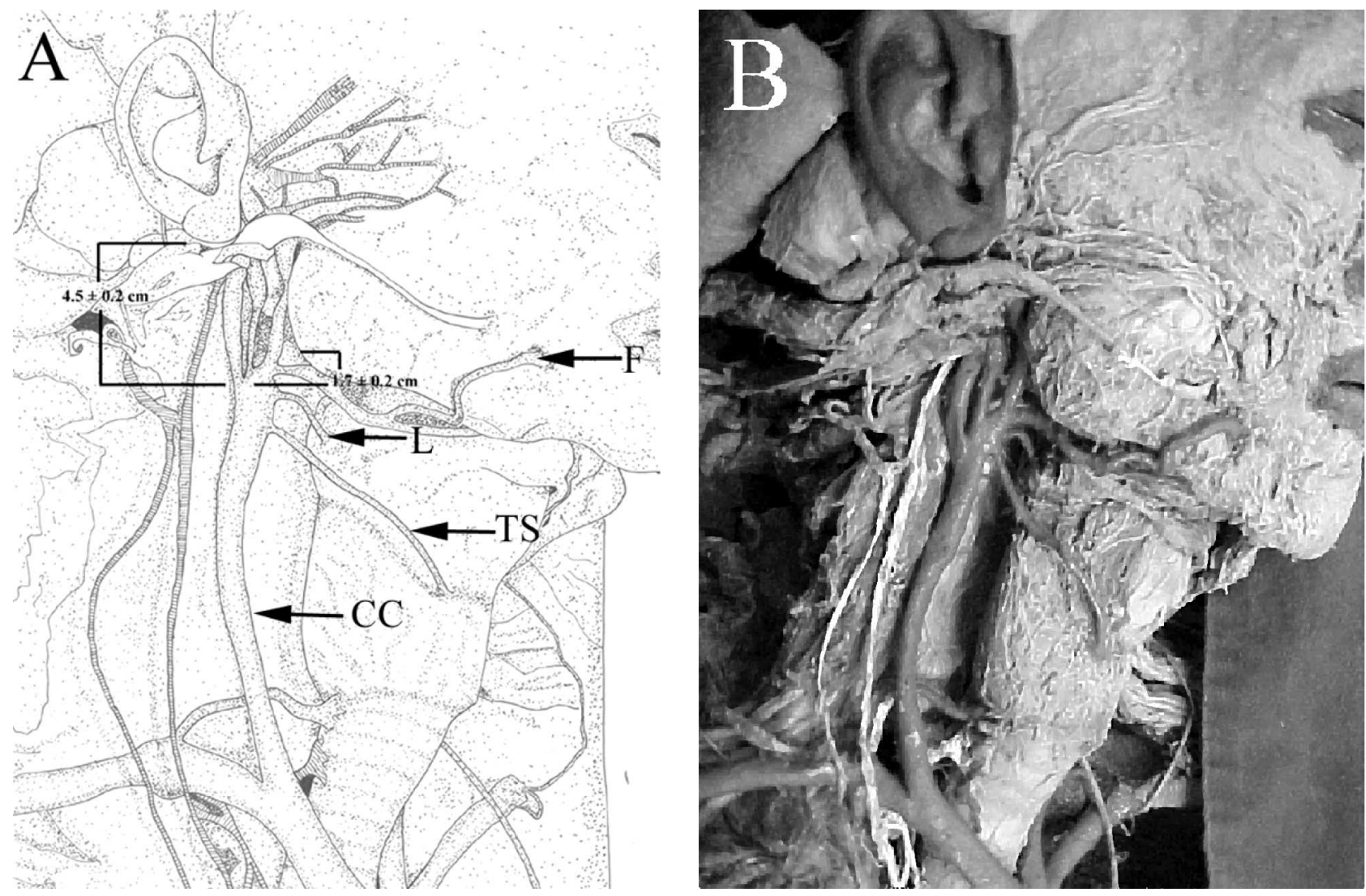

Fig. 1. Schematic drawing (A) of the lateral right view of the dissected neck shown in B. The measurements of the carotid artery bifurcation is shown in relation to the mandible angle and to the ear lobe. CCA. Common carotid artery; TS. Superior thyroid artery; L. Lingual artery; F. Facial artery. Note that the average distance from the CCA bifurcation was of $1.7 \pm 0.2$ $\mathrm{cm}$ from the mandible angle and $4.5 \pm 0.2 \mathrm{~cm}$ from the ear lobe.

Our results showed that the left CCA is longer than the right one. This was expected because of the asymmetrical origin of these vessels. The diameters of the CCA at origin and bifurcation were similar between sides but larger at bifurcation level than the origin level on both sides. This is also in agreement with the general anatomical description of these vessels. Nevertheless, this study provides the measurements of these diameters, which are not frequently encountered in the literature. The diameters of the ECA were significantly smaller than those for the ICA, again in agreement with the general description of these vessels, with this study providing the numeric variations of these diameters. Although formalin fixed cadavers were used in the current study, the vessel diameter data can be considered valid because they do not differ from those reported in studies carried out on fresh cadavers (Affeld et al., 1998) or in vivo non invasive methods for accessing the arterial diameters (Bandyk et al., 1958). The differences found on the bifurcation levels diameters between our results and those of Affeld et al., are probably due to the difference on the level where measurements were done.
From the bifurcation landmarks studied, the cervical vertebra was the most variable one, including differences between sides, even though most of the radiological literature continues to use them as a landmark of the CCA bifurcation (Smith \& Larsen, 1979; Lemmi et al.). Our study shows that the superior border of the thyroid cartilage was the most stable anatomical landmark for predicting the CCA bifurcation level. The mandible angle and the ear lobe landmarks variability were larger than the thyroid cartilage level but much smaller than the cervical vertebra level. It is important to mention that from all the landmarks studied, the cervical vertebra was the only one to show differences between sides.

Arterial diameter is an indicator of blood flow and is therefore relevant in ensuring good reperfusion of local structures during reconstructive surgeries. Information on normal arterial diameters as we have reported is also important in relation to changes in response to drugs or different treatments, or alterations in diseases, such as hypertension, artheriosclerosis and diabetes. 
Acknowledgements:We thank the late Mr. Arnaldo Geraldino, from the Human Anatomy Discipline, Federal University of Triângulo Mineiro, for his excellent technical support while the study was carried out. Rogério Alves Ribeiro was the recipient of a fellowship from CNPq while the study was carried out.

RIBEIRO, R. A.; RIBEIRO, J. A. S.; RODRIGUES FILHO, O. A.; CAETANO, G. A. \& FAZAN, V. P. S. Niveles de bifurcación de la arteria carótida común en relación a puntos de referencia anatómicos relevantes en clínica. Int. J. Morphol., 24(3):413-416, 2006.

RESUMEN: En cirugías de cabeza y cuello, las arterias carótidas comunes son importantes puntos de referencia, para defnir el plano de disección, durante cirugías radicales de cuello. Los objetivos del presente estudio fueron agregar información sobre el diámetro de las arterias carótidas y correlacionar el nivel de bifurcación de la arteria carótida común (ACC) con importantes puntos de referencia usados regularmente en la práctica clínica.

Para la obtención de los objetivos planteados, fueron evaluados 46 cadáveres formolizados de individuos de sexo masculino. Se obtuvieron los diámetros de las arterias carótidas común, externa (ACE) e interna (ACI), con el auxilio de un caliper digital. No hubo diferencias entre lados derecho e izquierdo, ni tampoco en los niveles estudiados. El nivel de bifurcación de la ACC fue medido en relación a puntos de reparos anatómicos relevantes en clínica (margen superior del cartílago tiroides, ángulo de la mandíbula y lóbulo del pabellón auricular), como también en relación al nivel vertebral.

Nuestro estudio mostró que el margen superior del cartílago tiroides fue el punto de referencia más estable para inferir el nivel de bifurcación de la ACC. Es importante mencionar que, de todos los puntos de referencia estudiados, la vértebra cervical fue la única que mostró diferencias entre los lados, siendo más variable el nivel de bifurcación en el lado izquierdo.

\section{PALABRAS CLAVE: Anatomía vascular; Anatomía quirúrgica; Cirugía de cuello; Arteria carótida; Diámetro arterial.}

\section{REFERENCES}

Affeld, K.; Goubeergrits, L.; Fernandez-Britto, J. \& Falcon, L. Variability of the geometry of the human common carotid artery. A vessel cast study of 31 specimens. Pathol. Res. Pract., 194:597-602, 1998.

Agur, A. M. R. \& Lee, M. J. Grant's Atlas of Anatomy. $9^{\text {th }} \mathrm{ed}$. Baltimore-USA, Williams \& Wilkins, 1991.

Bandyk, D. F.; Levine, A. W.; Pohl, L. \& Towne, J. B. Classification of the carotid bifurcation disease using quantitative Doppler spectrum analysis. Arch. Surg., 120:306-14, 1985.

Fazan, V. P. S.; Caetano, A. G. \& Rodrigues Filho, O. A. Anomalous origin and cervical course of the vertebral artery in the presence of a retroesophageal right subclavian artery. Clin. Anat., 17: 354-7, 2004.

Fazan, V. P. S.; Ribeiro, R. A.; Robeiro, J. A. S. \& Rodrigues Filho, O. A. Right retroesophageal subclavian artery. Acta Cir. Bras., 18 (Suppl. 5):54-6, 2003.

Lemmi, H.; Daly, R. F.; Kashgarian, M. \& Argires, J. A comparison of the level of bifurcation of the common carotid arteries in Negroes and Whites. Acta Anat., 71:22-7, 1968.

Ong, L. D. \& LeClare, P. C. The Kolmogorov-Smirnov test for normality of sample cumulative frequency distributions. Health. Phys., 14:376, 1968.

Ord, R. A. \& Ward-Booth, R. P. Anomalies of the common carotid artery: A rare complication of radical neck dissection. Brit. J. Oral Max. Surg., 24:405-9, 1986.
Rosenthal, R. An application of the Kolmogorov-Smirnov test for normality with estimated mean and variance. Psychol. Report, 22:570, 1968 .

Schwartz, R. B.; Jones, K. M.; Chernoff, D. M.; Mukherji, S. K.; Khorasani, R.; Tice, H. M.; Kikinis, R.; Hooton, S.; Stieg, P. E. \& Polak, J.F. Common carotid artery bifurcation: Evaluation with spiral CT. Radiology, 185:513-9, 1992.

Smith, D. \& Larsen, J. L. On the symmetry and asymmetry of the bifurcation of the common carotid artery. A study of bilateral carotid angiograms in 100 adults. Neuroradiology, 17:245-7, 1979.

Vitek, J. J. \& Reaves, P. Thoracic bifurcation of the common carotid artery. Neuroradiology, 5:133-9, 1973.

Wilcoxon, F. Individual Comparisons by Ranking Methods. Biometrics, 1:80-3, 1945.

Correspondence to:

Valeria Paula Sassoli Fazan, M.D. P., Ph.D.

Assistant Professor

Department of Surgery and Anatomy

School of Medicine of Ribeirão Preto, USP

$\mathcal{A} v$. Bandeirantes 3900

CEP:14049-900.

Ribeirão Preto, $S P$,

BRAZIL

Email:vpsfazan@fmrp.usp.6r

Received :26-04-2006 vpsfazan@yahoo.com.6r 